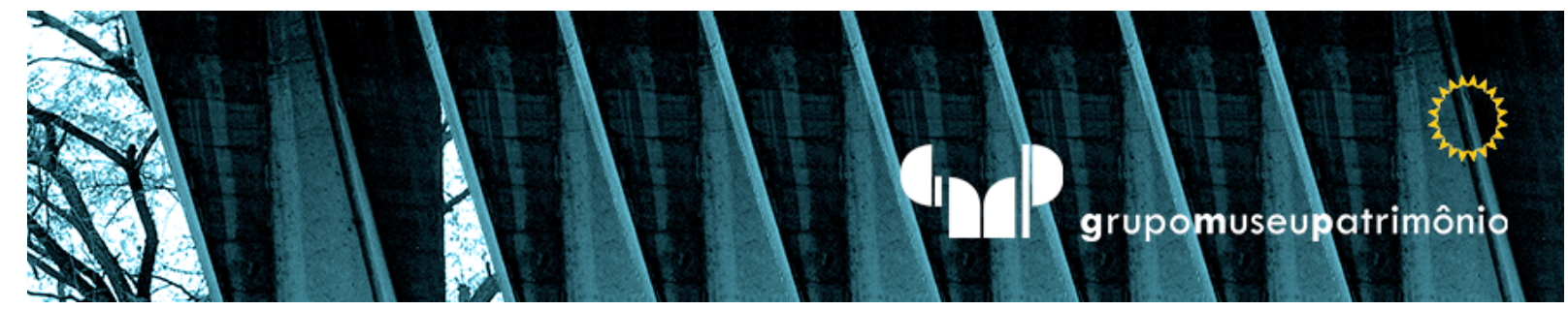

\title{
Horizontes da visualidade: um ensaio visual acerca das fronteiras patrimoniais no Le Louvre-Lens
}

\author{
Horizontes visuales: un ensayo visual \\ sobre los límites patrimoniales en \\ Le Louvre-Lens
}

Visual horizons: a visual essay on heritage boundaries at Le Louvre-Lens 


\section{Resumo}

Os encontros com a arte, quase sempre, nos levam às fronteiras do sensível e seus espaços tendem a ser desvios do cotidiano. Esse ensaio pretende abordar um episódio muito peculiar: minha visita, em 2017, ao Le Louvre-Lens. Um museu surpreendente - por sua distância da pólis, por sua arquitetura indutora ao desconforto dos hábitos, por sua expografia plena de high-lights artísticas e pela vocação de diversificação e multiplicação do patrimônio cultural irradiado de sua célula-mãe, o Musée du Louvre de Paris.

Palavras-Chave: Le Louvre-Lens. Fronteiras Patrimoniais. Horizontes da Visualidade. Ensaio Visual. Fotografia.

\section{Resumen}

Los encuentros con el arte casi siempre nos llevan a las fronteras de lo sensible y sus espacios tienden a ser desviaciones de la vida cotidiana. Y este ensayo tiene como objetivo abordar un episodio muy peculiar: mi visita, en 2017, a Le Louvre-Lens. Un museo sorprendente: por su distancia de la polis, su arquitectura que induce la incomodidad de los hábitos, su exhibición completa de luces artísticas y la vocación por la diversificación y multiplicación del patrimonio cultural irradiado de su célula madre, el Museo del Louvre de Paris.

Palabras clave: Le Louvre-Lens. Fronteras patrimoniales. Horizontes de la visualidad. Ensayo visual. Fotografía.

\section{Abstract \\ Encounters with art almost always lead us to the frontiers of the sensible and their spaces tend to be deviations from everyday life. And this essay aims to address a very peculiar episode: my visit, in 2017, to Le Louvre-Lens. A surprising museum - for its distance from the polis, its architecture that induces the discomfort of habits, its full exhibition of artistic high-lights and the vocation for diversification and multiplication of the radiated cultural heritage of its mother cell, the Musée du Louvre de Paris.}

Keywords: Le Louvre-Lens. Heritage borders. Horizons of Visuality. Visual essay. Photography. 


\section{APROXIMAÇÃo (RUMO AO NORTE)}

Em 29 de novembro de 2004, o primeiro-ministro Jean-Pierre Raffarin anunciou que a cidade de Lens foi selecionada como o local de boasvindas do novo Louvre. A escolha de instalar o museu no antigo fosso 9 de Lens marca o reconhecimento de toda a nação por um território várias vezes machucado, tanto pela exploração de carvão quanto pela guerra. Orgulhosa de seu passado mineiro e marcada por sua história, Lens se afirma como uma cidade envolvida em sua conversão.

(www. louvrelens.fr)

$\mathbf{P}$ artir de Paris rumo ao norte, quase alcançar a fronteira da França com a Bélgica e, antes, descer do trem na estação de Lens gera muita expectativa - talvez porque inexoravelmente se viverá a experiência de diluição de um mito: o legendário Musée du Louvre estava a pouco espaçotempo de ser confrontado com sua célula-filha: Le Louvre-Lens.

Era dezembro de 2017, a luz solar não arrefecia o frio. Mas a alma de um estudioso de arte (que nunca deixou de ser estudante) fervia de curiosidade e de emoção. A cidade, localizada na região de Pas-de-Calais e com mais ou menos 35 mil habitantes, é simpática aos desejos estrangeiros. Do chocolate quente com croissant à passarela do parque que conduz os visitantes ao 
museu o espaço-tempo se esvaneceu. Logo meu olhar tocou a superfície do museu.

Pensar que a justa integração parque-museu se dá no lugar de uma desativada mina carvoeira, anteriormente colorida de fuligem, dignifica a nova paisagem de horizonte azul diurno, de gramado verde-claro e contorno de árvores marrom invernal. No centro irradiador da cena se configura a edificação vítrea do Louvre-Lens.

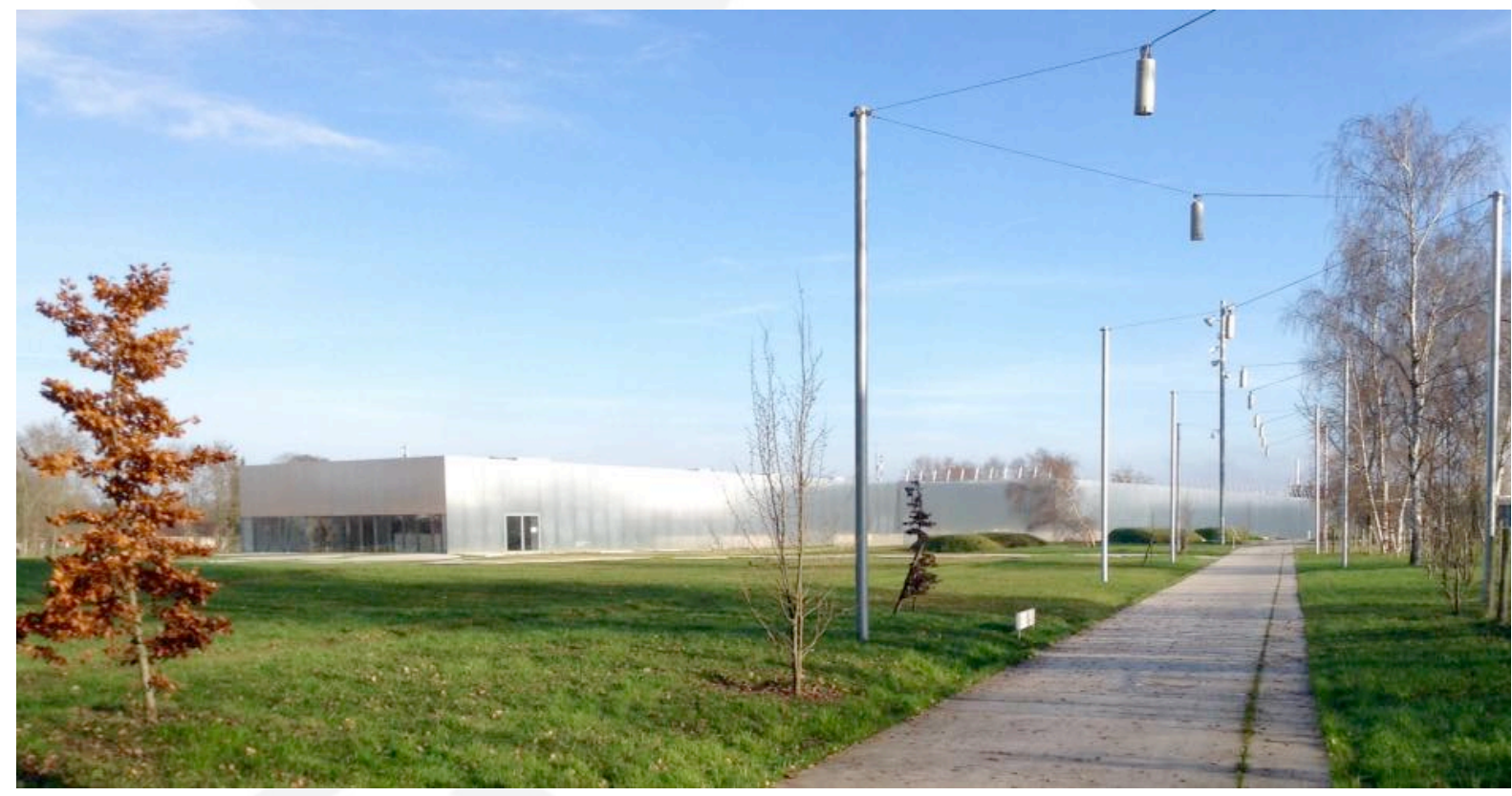

Figura 1: A configuração do parque de 20 hectares promove a orgânica relação do museu com o seu entorno. Fonte: Marcos Rizolli.

Conforme se aproxima, apesar de sua horizontalidade, mais imponente e misteriosa se desenha a edificação. O espaço algo desmaterializado, tatilmente nos atrai. Os passos se aceleram ao encontro de uma inevitável e orgânica interação com a arte.

A percepção, alterada, abre uma outra fronteira entre o exterior e o interior. Assim, como a arte, o Louvre-Lens é a vida outra vez! Ao mesmo tempo, o edifício parece ser uma fortaleza medieval ou uma caixa contemporânea. 

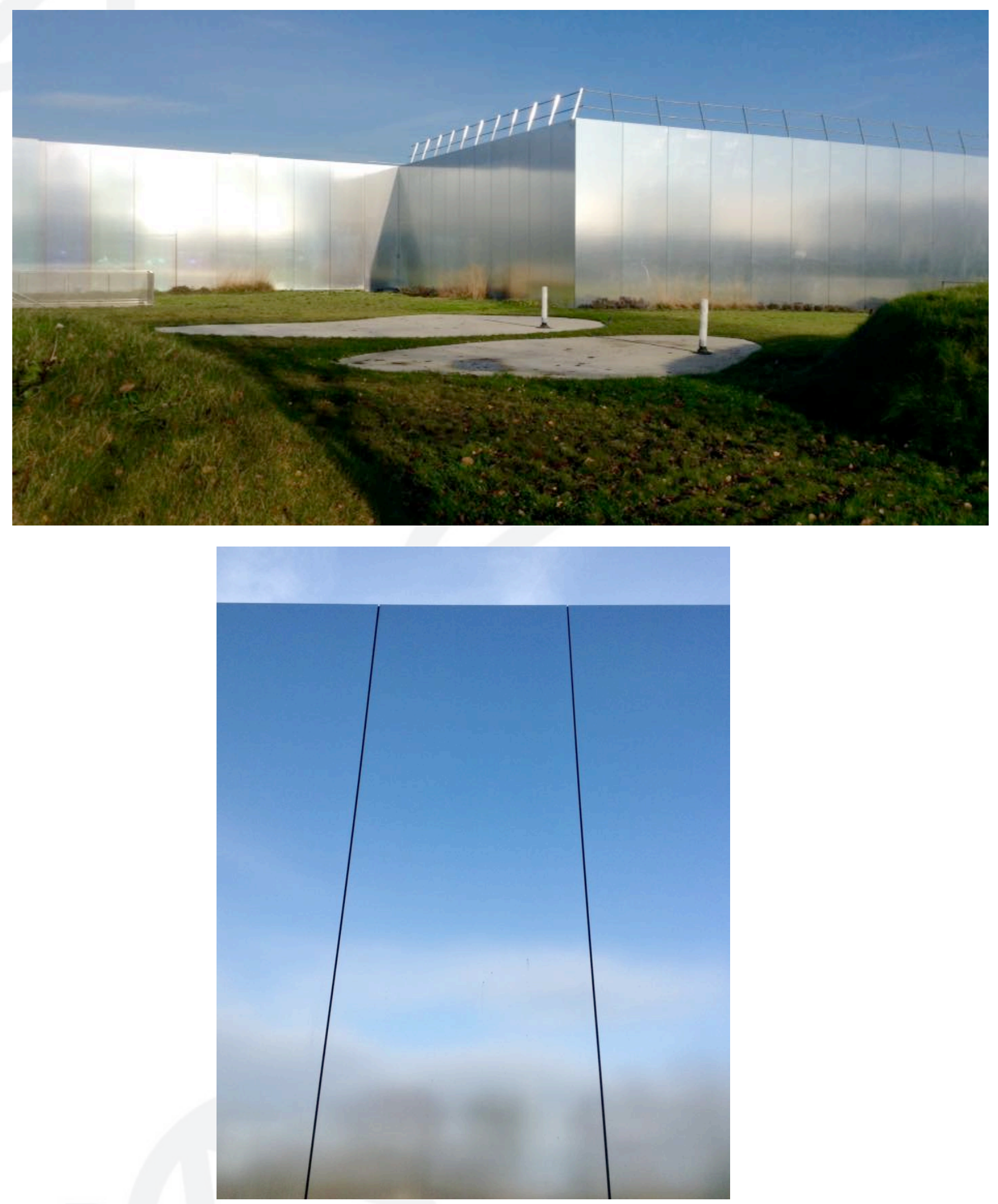

Figuras 2 e 2a: As paredes de vidro do museu não apresentam janelas e somente duas portas destinadas ao acesso público; Pormenor das placas de vidro da fachada.

\author{
Fonte: Marcos Rizolli.
}



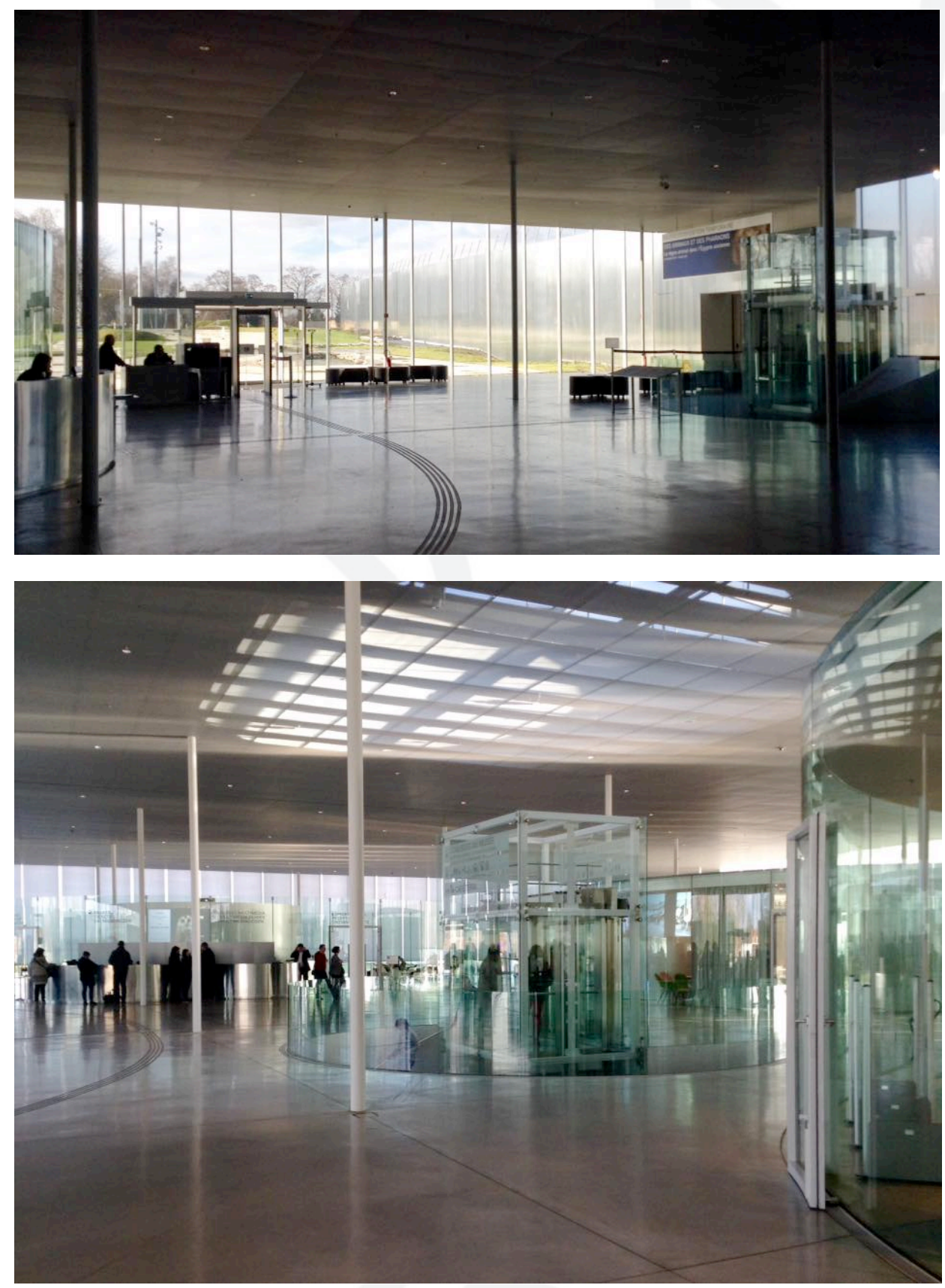

Figuras z e 3a: O parque pode ser visto do interior do museu, cuja arquitetura em vidro permite o jogo entre transparência e opacidade. Fonte: Marcos Rizolli.

O delicado equilíbrio entre razão e emoção, entre conforto e risco se apresenta. E nos arremessa para uma experiência ímpar: caleidoscópica. Paradoxalmente, nossa percepção apreende fenômenos contemplativos (imagens fixas em suportes tradicionais, algo distanciadas), interacionistas 
(instalações que solicitam uma fruição participativa, algo aproximadas) e interativos (sistemas em que os dispositivos maquínicos apresentam-se como entes mediadores da relação obra-visitante). O efeito caleidoscópico permite uma percepção multidimensional - positivamente saturada por rebatimentos. Acerca disso, as imagens bem estarão aptas a nos informar! Vejamos:

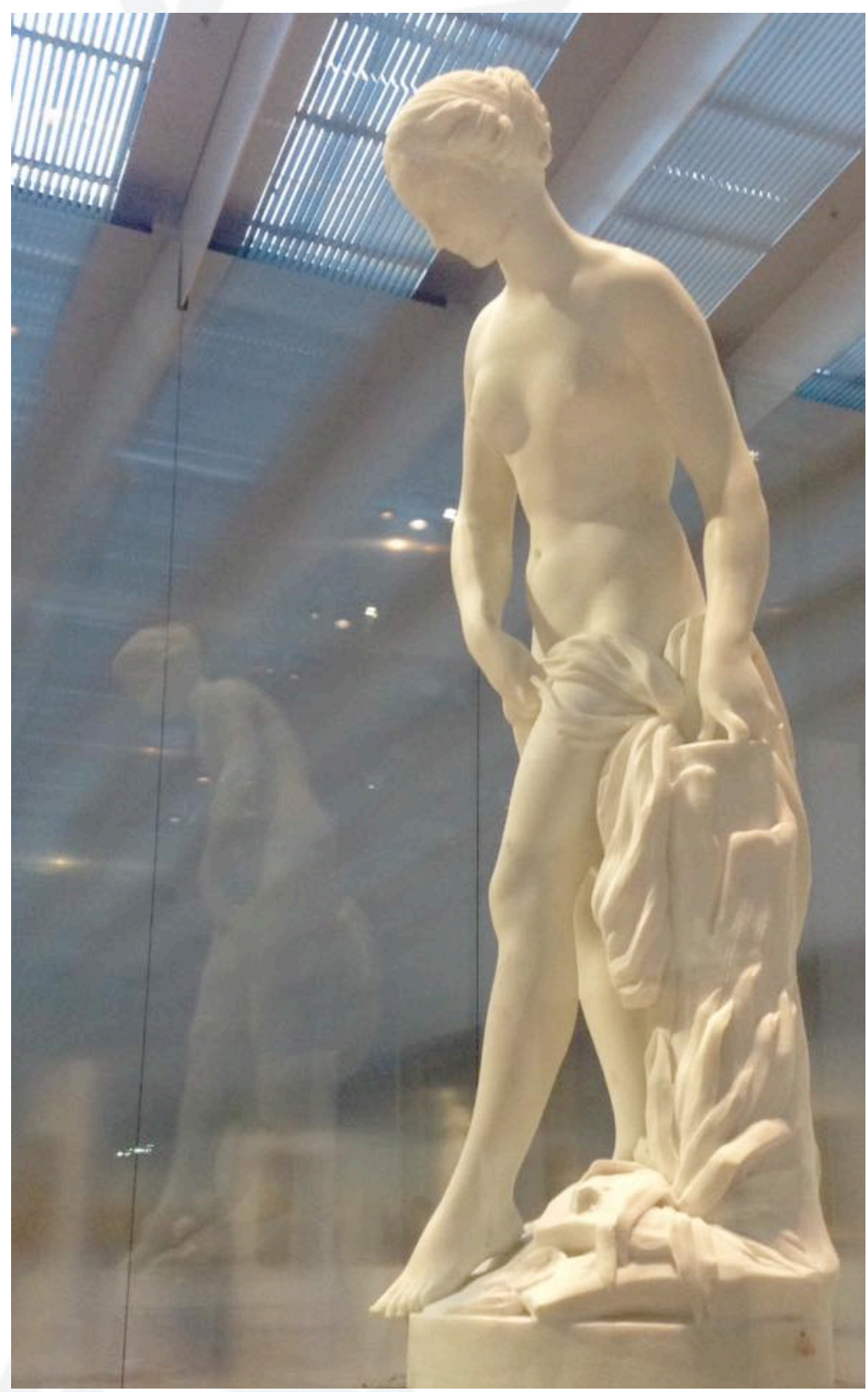

Figura 4: Na sala do Tempo, esculturas convivem com seus duplos projetados nas paredes espelhadas. Fonte: Marcos Rizolli. 


\section{INTERAÇÃO (ENTRE TRANSPARÊNCIAS E OPACIDADES)}

As cerca de 500 a 600 obras de arte que são expostas no Louvre-Lens, sempre em caráter temporário e em rodízio com o Louvre-Paris, são expograficamente distribuídas nos 18 mil metros da sede. Os espaços, todos integrados, permitem a comunicação das obras consigo mesmas (acentuando-se as tensões figurais, cromáticas e formais, compositivas, técnicas e expressivas), entre elas (no arco da história e da cultura), com o público expectador (que tem alcançado a média anual de cerca de 600 mil visitantes), com a arquitetura (concebida em vidros fotoelétricos que, considerando as codições climáticas e o desejo curatorial, podem reconhecer transparência ou opacidade) e com o parque (estrategicamente distanciado do núcleo urbano e, assim, imerso na natureza).

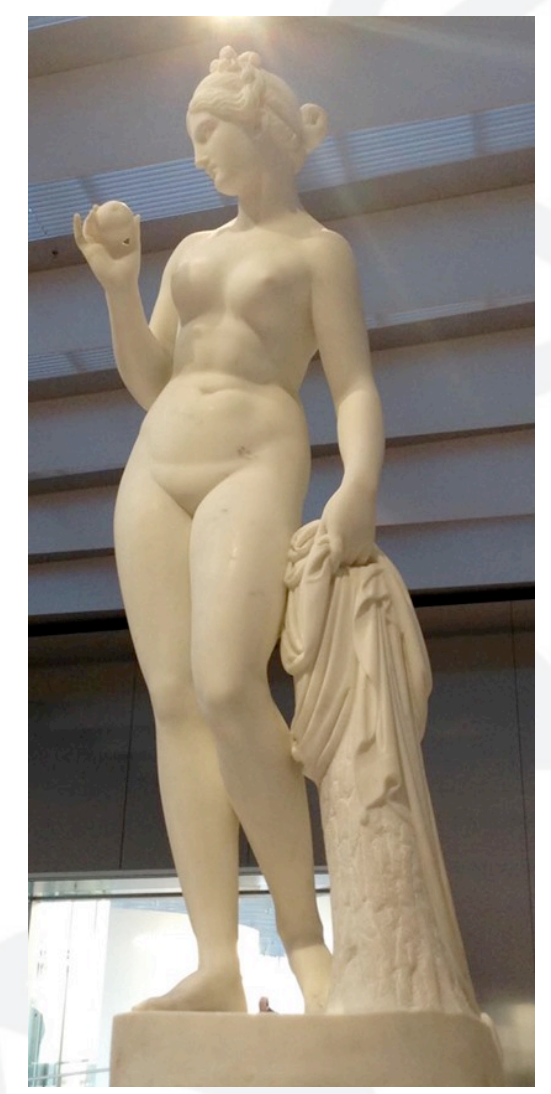

Figura 6: A expografia do Louvre-Lens garante o protagonismo e a contemplação das obras. Fonte: Marcos Rizolli. 

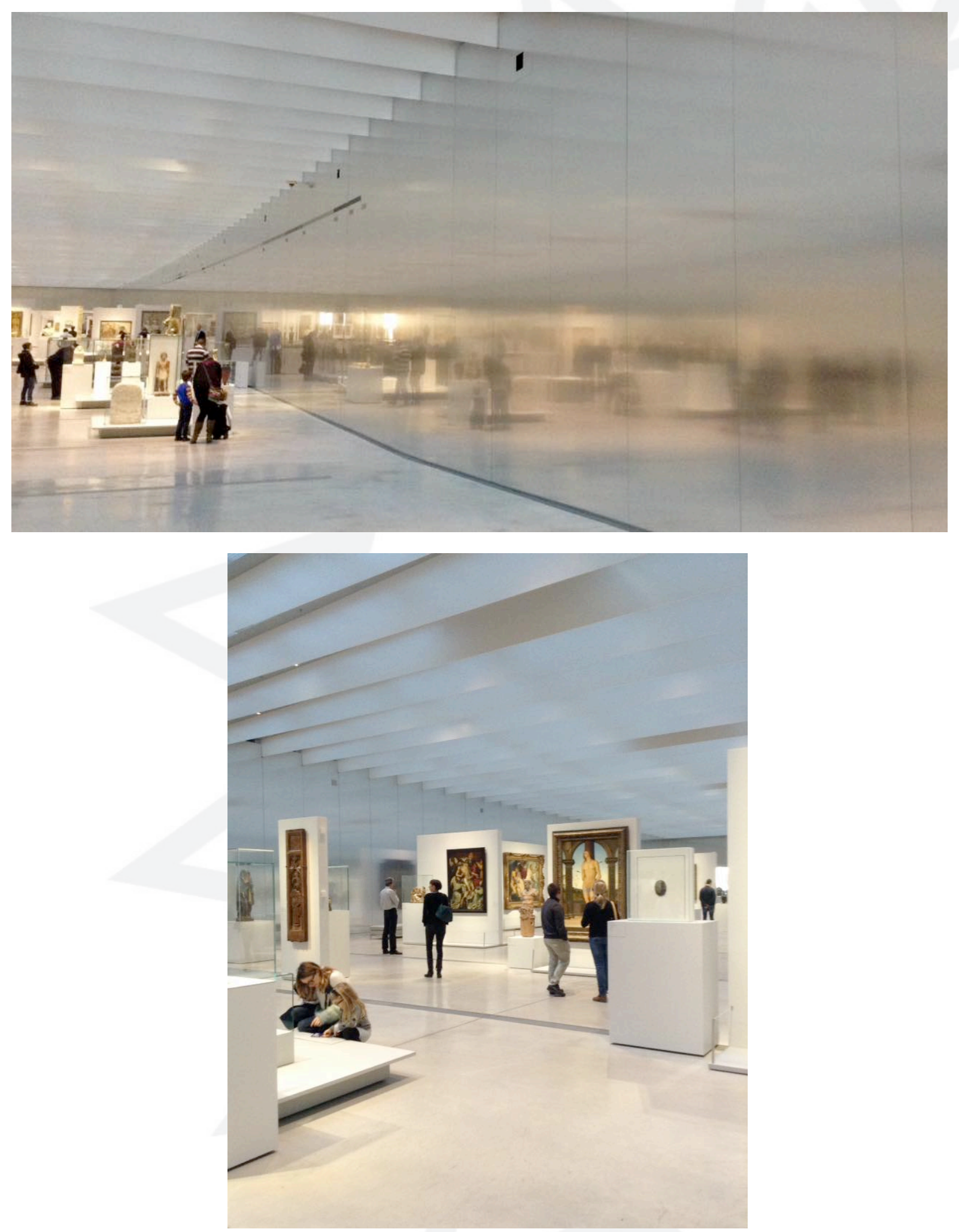

Figuras 7 e 8: A arte, o público e o espaço arquitetônico propiciam surpreendente encontro com a arte. Fonte: Marcos Rizolli. 


\section{A ARTE E SUAS INSTÂNCIAS (HORIZONTES DA VISUALIDADE)}

O advento do Louvre-Lens sinaliza para a potência e mutabilidade dos fenômenos artísticos que deflagram dimensões culturais, patrimoniais e institucionais. O significativo acervo de arte sob custódia do governo nacional francês projeta-se para novas instâncias - desenhando novos territórios e abrindo novas fronteiras.
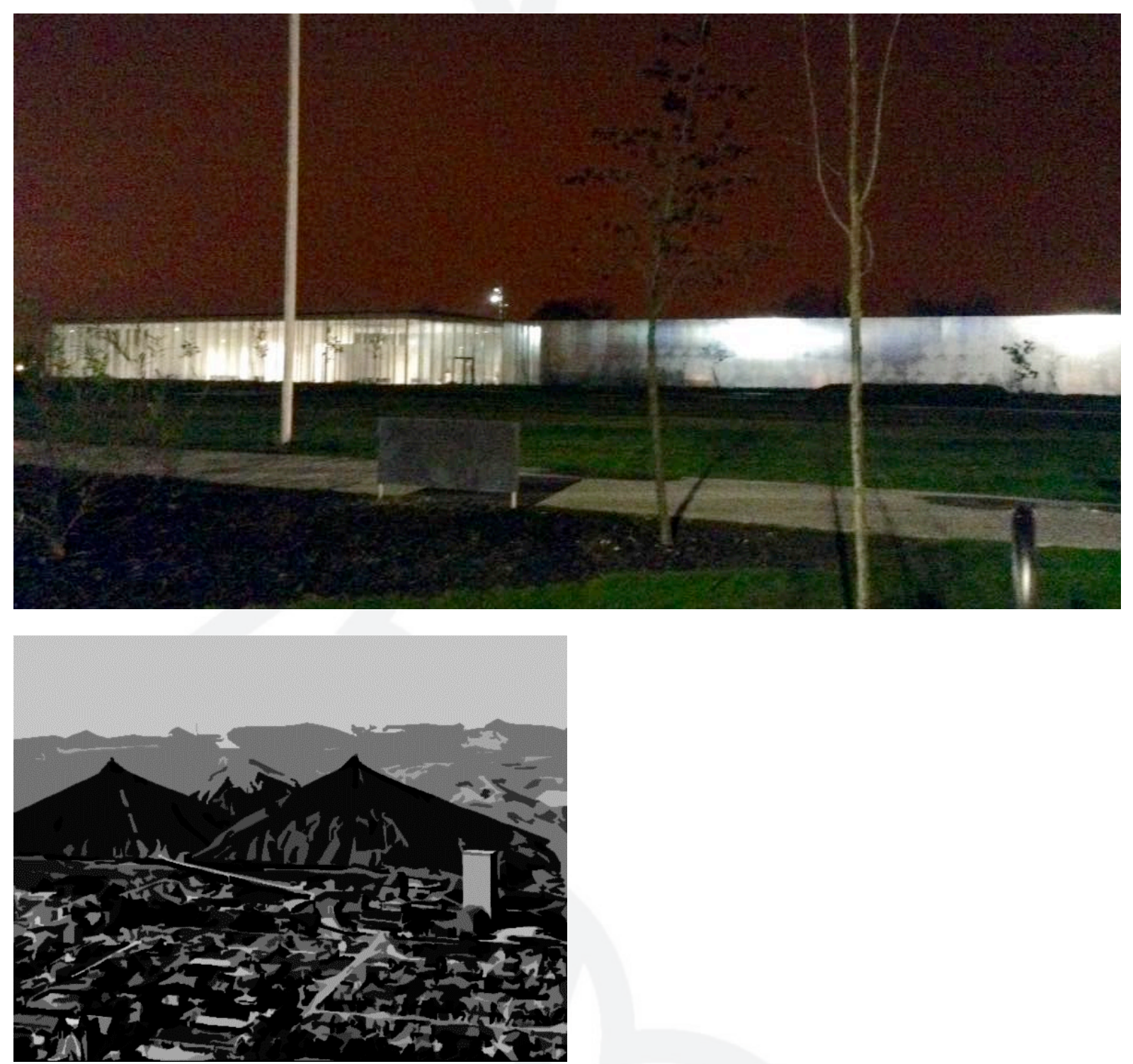

Figuras 10 e 11: A penumbra da noite em contraste com as luzes evanescentes do museu reafirmam o contraste vocacional do lugar: a cinza e densa paisagem carvoeira cede às vicissitudes da arte. Fontes: Marcos Rizoll e ilustração a partir do Arquivo Le Louvre-Lens 
Assim, os horizontes da visualidade se expandem e ocupam novos olhares e novas consciências.

O Louvre-Lens detém inúmeras virtudes: novo e inovador, distante e próximo (geográfica e simbolicamente) ao mesmo tempo, natureza e arquitetura, transparente e opaco, antigo e contemporâneo, orgânico e tecnológico, fato e futuro... arte e conhecimento.

E por fim, espero que este ensaio visual possa cumprir a máxima de T. S. Eliot - $O$ que chamamos princípio é quase sempre o fim. E alcançar um fim é alcançar um princípio. Fim é o lugar de onde partimos - tão bem evocada por Gregori e Rocha.

\section{REFERÊNCIAS}

https://www.louvrelens.fr/le-louvre-lens/lhistoire-du-louvre-lens/ [acesso em 18 ago. 2019].

https://villedelens.fr/ [acesso em 18 ago. 2019]. 